\title{
La educación técnica superior durante el primer peronismo: un balance historiográfico en torno a la Universidad Obrera Nacional
}

Higher technical education during the first peronism: a historiographic balance around the Worker National University (Universidad Obrera Nacional)

Álvaro Sebastián Koc Muñoz ${ }^{1}$

Resumen: El objetivo del presente trabajo es realizar un balance historiográfico en torno a los distintos estudios realizados sobre la Universidad Obrera Nacional (UON). En tal sentido, se analizarán las interpretaciones y reflexiones teóricas realizadas en torno a esta institución, a la luz de nuevos trabajos publicados sobre este tema. Para ello, se analizarán las distintas producciones sobre esta institución como asimismo las realizadas sobre la Comisión Nacional de Aprendizaje y Orientación Profesional, comisión de la cual dependía la UON y que constituye un antecedente necesario de esta. El análisis propuesto no pretende ser exhaustivo, sino que busca trazar las líneas de discusión en las cuales inscribir una futura investigación, cuyo tema de estudio es la transformación de la Universidad Obrera en Universidad Tecnológica, en el marco de la autodenominada "Revolución Libertadora" y del gobierno constitucional de Frondizi en un segundo momento.

Palabras clave: historiografía, Argentina, universidad, trabajador industrial, educación obrera.

\footnotetext{
${ }^{1}$ Licenciado y Profesor en Sociología. Becario doctoral CONICET. Docente de la Escuela de Educación Secundaria Técnica no 6 "Albert Thomas". La Plata, Buenos Aires, Argentina.

E-mail: sebastiankoc84@gmail.com.
}

Diälagas Pedagágicas. ISSN en línea: 2524-9274

Año XVI, No 32, octubre 2018-marzo 2019. Pág. 106-124

DOI: http://dx.doi.org/10.22529/dp.2018.16(32)07 / Recibido: 21-06-2018 / Aprobado: 24-09-2018

cc)(-) $\Theta$ Artículo publicado bajo Licencia Creative Commons Atribución-NoComercial-SinDerivar. (c) Universidad Católica de Córdoba. 


\begin{abstract}
The objective of this work is to present a historiographic balance around the various studies of the Universidad Obrera Nacional (The Worker National University). Accordingly, interpretations and theoretical reflections carried out around this institution will be analized, in the light of new published works on this topic. To do so, different productions about this institution will be considered as well as those carried out on the CNAOP, Commission of which depended the UON and which constitutes a necessary antecedent of it. The proposed analysis is not intended to be exhaustive, but rather seeks to trace the lines of discussion in which sign a future investigation, whose theme of study is the transformation of the Workers' University into Technological University, within the framework of the self-proclaimed "Liberating Revolution" and of the constitutional government of Frondizi in a second moment.
\end{abstract}

Key words: historiography, Argentina, University, industrial worker, workers' education.

\title{
Introducción
}

La creación de la Universidad Obrera Nacional (UON) a través de la Ley 13229/ 48 , durante el primer gobierno de Perón, ha sido un punto de fuerte polémica en la historiografía educativa argentina, que generó un debate que mantiene su vigencia hasta nuestros días.

Cabe destacar que estos trabajos fueron realizados en su mayoría por autores pertenecientes tanto al campo de las ciencias de la educación como al campo de la historia, siendo muy marginal el aporte realizado desde otras disciplinas científicas. La mayoría de estos estudios abordan este tema de manera tangencial, en el marco de estudios más generales sobre la educación durante el primer peronismo, siendo pocos los trabajos que se abocan al estudio estrictamente de la Universidad Obrera; y de estos, solo algunos ofrecen un análisis de esta institución en el marco de los gobiernos postperonistas y la consiguiente reconversión de la Universidad Obrera en Universidad Tecnológica Nacional (UTN).

En líneas generales puede afirmarse que la discusión sobre la cual se asientan los estudios arriba mencionados gira en torno a un debate de carácter más general que atraviesa todo el campo de la educación y sobre el cual se estructuró el campo de la historia de la educación en Argentina. Cecilia Braslavsky (1985) lo sintetiza de la siguiente manera:

Los sistemas de educación formal son una de las redes institucionales más extendidas y costosas de todos los países del mundo. Son, sin embargo, uno de los conjuntos de sistemas sobre cuya función social existe menos consenso. Para algunos son el paradigma de red institucional al servicio de las transformaciones social. Para otros son, en cambio, el paradigma de los mecanismos de la reproducción de un orden social cuyo centro es la dominación de determinados grupos, sectores o clases sociales sobre otros. (Braslavsky, 1985, p. 9) 
Es, en esta línea de trabajo, que las políticas de ampliación e implementación del sistema de educación técnica oficial a partir de 1944 han sido analizadas por los distintos autores. Desde una perspectiva analítica e histórica pueden rastrearse dos grandes tendencias historiográficas que polarizan este debate. Estas polemizan sobre la finalidad subyacente a las propuestas de diversificación del sistema educativo que incorporaban modalidades técnicas. Tenemos, por un lado, la tendencia a la que podríamos denominar discriminadora/desviacionista que parte de considerar que todo intento de modificación del curriculum clásico humanista es esencialmente discriminador. La diversificación del sistema educativo aparece aquí como una estrategia política de las élites dirigentes cuya finalidad sería "desviar" a los sectores sociales en ascenso de la universidad para -de esta manera- mantener el monopolio de los saberes socialmente válidos para el ejercicio del poder político. Por otro lado, una segunda tendencia historiográfica, a la que podríamos denominar democratizadora, enfatiza la potencialidad de las políticas educativas mencionadas para impulsar la promoción social de los actores involucrados. La vinculación educación-trabajo y las propuestas de diversificación del sistema responderían, desde esta mirada, a las demandas de los sectores sociales no incluidos hasta el momento. En el presente análisis bibliográfico utilizaremos estas dos categorías y añadiremos una tercera para aquellos trabajos que no pueden ser clasificados bajo estas y a la que denominaremos Trabajos del "nuevo milenio" sobre la UON. En esta categoría serán incluidos estudios de diversa índole, que no registran ningún tipo de discusión con aquellos comprendidos en las categorías anteriormente mencionadas como tampoco diálogo entre sí. Asimismo, estos trabajos publicados con posterioridad al año 2000 tienen como principal característica la heterogeneidad y la diversidad utilizadas y las fuentes analizadas.

\section{Tendencia historiográfica discriminadora/desviacionista}

Dentro de esta tendencia historiográfica, el primer estudio en hacer referencia a la UON es el ya clásico trabajo sobre el movimiento reformista universitario 20 años de movimiento estudiantil reformista (1943-1963) de Bernardo Kleiner (1964). Según el autor la creación de la UON, por parte del gobierno peronista, vendría a ser el punto más álgido de la lucha de los trabajadores y de las demandas del movimiento reformista. Pero, al mismo tiempo, Kleiner sostiene que si bien la UON fue la cristalización de las demandas obreras y del movimiento estudiantil reformista es, al mismo tiempo, una creación que no se asentaba sobre un reclamo popular, sino, más bien, aparece como una estrategia del gobierno y de la burguesía y pequeña burguesía de desviar a los hijos del proletariado de la universidad. En el análisis de Kleiner conviven de manera contradictoria y rudimentaria ambas tendencias historiográficas, aunque el énfasis parece estar puesto en la tesis de la desviación.

El trabajo de Tedesco (1980) es el primero en sostener un posicionamiento explícito en este debate. Este autor, basándose en la existencia de saberes socialmente válidos, sostiene que las propuestas de diversificación del sistema educativo argentino fueron de carácter discriminatorio y responden a una política reproductora y diferenciadora (ver Tedesco, 1986). Su tesis principal es que el 
sistema educativo nacional, constituido a fines del siglo XIX, tenía un carácter más político que económico ya que las necesidades técnicas de la incipiente industria argentina eran cubiertas por personal extranjero proveniente del proceso migratorio masivo de principios del siglo XX. Los sucesivos intentos de reformas del sistema educativo propuestos en las primeras décadas por Magnasco y Saavedra Lamas, entre otros, darían cuenta de las crisis por las que atravesó el sistema, generando distintas propuestas de diferenciación de la enseñanza media y posprimaria basadas en la creación de circuitos profesionales y técnicos de carácter terminal, a fin de desviar a los sectores sociales en ascenso del acceso a la universidad. El autor al referirse, de manera general, al crecimiento de la matrícula de las escuelas dependientes de la Comisión Nacional de Aprendizaje y Orientación Profesional (CNAOP) menciona dos periodos en el desarrollo de este circuito. El primero, desde su creación (1944) hasta 1950 aproximadamente, se centró en la formación de operarios medios con estudios terminales de corta duración, en la articulación con el trabajo, y organizativamente se desenvolvió en un ámbito diferente al del Ministerio de Educación, ya que dependía del Ministerio de Trabajo. El segundo período marca la dilución de estos rasgos, la equiparación de este circuito con el de la enseñanza técnica tradicional y la tendencia a incrementar la duración de los estudios. La Universidad Obrera correspondería a esta etapa. Para Tedesco (1980) las explicaciones economicistas no pueden dar cuenta de este hecho por los requerimientos de la producción ya que, en un primer momento la baja complejidad tecnológica no constituyó un estímulo al desarrollo de la enseñanza técnica debido a los escasos requerimientos de calificación y la alta complejidad tecnológica tampoco lo fue por el número escaso de personal que puede ocupar. En suma, según Tedesco, el grado de complejidad tecnológica no es una variable suficiente para explicar las alternativas en la dinámica del crecimiento de la enseñanza técnica. En este sentido, si las causas económicas no son lo suficientemente explicativas para comprender este cambio en la orientación de la CNAOP debe recurrirse a las de orden político-social. Para el autor hay una constante en la historia de la educación argentina, y es que

ningún grupo social en ascenso admite modalidades educativas que por su carácter terminal no habiliten para estudios posteriores. La presión para que esas vías continúen hasta los niveles más altos suele ser intensa y, en este caso, se concentraron tanto a través de la creación de una instancia específica de tipo terciario (la UON) destinada a permitir el pasaje de los egresados de la CNAOP al nivel universitario, como por la progresiva pérdida de las características originales del proyecto. (Tedesco, 1978, p. 22)

Ante los proyectos limitacionistas y segregadores, los grupos sociales emergentes habrían contestado con una opción más decidida hacia aquellos circuitos proveedores de las credenciales necesarias para una incorporación plena a la sociedad.

Otro exponente en esta línea interpretativa es Gregorio Weinberg (1984), quien realiza un análisis sobre la educación en el marco de un estudio más general sobre el populismo en América Latina. Según el autor las características generales del populismo pueden encontrarse en el campo del proceso educativo. En este 
sentido, los parasistemas educativos creados por los populismos (para el caso del peronismo la CNAOP) responderían a la presión de los nuevos actores sociales que pujan por ser incluidos dentro del sistema educativo; son circuitos constituidos para el adiestramiento de la mano de obra y sobre todo son sistemas sin perspectivas. En suma, para Weinberg, la UON puede ser catalogada como una universidad de "segunda categoría" (Weinberg, 1984, p. 122) dado que esta constituiría una respuesta -improvisada- por parte del Estado a la creciente presión política de los sectores sociales en ascenso.

Por su parte, el trabajo de Norma Novelli (1986) se centra en el estudio del movimiento estudiantil de la UON-UTN en el periodo 1953-59 y en la lucha que sostuvo este a partir de 1955 en torno a las demandas de autonomía y jerarquización del título. Para la autora, al igual que para Kleiner, la Universidad Obrera es una institución que ya estaba contenida en las demandas del movimiento reformista. Sin embargo, la creación de esta, por parte del gobierno peronista, la redujo a una institución con un cierto "tinte demagógico" (Novelli, 1986 , p. 3). En suma, para la autora, la UON no constituía una "verdadera" universidad. Si bien fue parte de las demandas del movimiento reformista, su creación por parte del gobierno peronista la redujo a una mera institución "demagógica". No obstante ello, gracias a la lucha llevada adelante por los alumnos y los profesores de esta casa de estudios, se sancionó la ley de creación de la Universidad Tecnológica Nacional, con la cual adquiría una "real categoría universitaria" (Novelli, 1986, p. 29).

Asimismo, uno de los más importantes referentes de la línea interpretativa desviacionista dentro de la historiografía es Mariano Plotkin (1993). Según el autor el circuito de educación técnica CNAOP-UON era reaccionario ya que seguía una línea de clase bien definida y no permitía cruces con el sistema educativo tradicional. En este sentido, el autor es categórico al afirmar que Perón pudo lograr lo que ningún gobierno conservador anterior a él había podido, quitándole a este gobierno todo sesgo democrático y popular, al menos en el campo educativo.

Por último, cabe destacar que al interior de esta tendencia pueden identificarse dos subgrupos de trabajos. Por un lado, aquellos trabajos que se caracterizaría por poner el foco en la desviación propiamente dicha, es decir, en la idea de que el circuito educativo creado por el peronismo buscaba "desviar" a los sectores sociales en ascenso de las universidades clásicas; a este grupo pertenecerían los trabajos de Kleiner, Tedesco y Plotkin. El otro subgrupo se caracterizaría por poner el énfasis en la idea de "demagogia", como característica propia de los gobiernos populistas; a este último grupo pertenecerían los trabajos de Weinberg y Novelli.

\section{Tendencia historiográfica democratizadora}

Dentro de esta segunda tendencia historiográfica, el primer trabajo al que haremos referencia es "Peronismo, saber y poder" de Juan Balduzzi (1987). Si bien no menciona específicamente a la UON, su análisis sobre la CNAOP constituye para esta tendencia historiográfica un antecedente insoslayable. En este texto, el autor analiza el lugar ocupado por el saber en el discurso peronista en el marco 
del esfuerzo de aquel movimiento por construir una nueva hegemonía: se plantea explorar esa relación entre peronismo y saber a través del análisis de lo que él caracteriza como "legislación fundadora" del movimiento peronista, esto es, las leyes de creación de la Secretaría de Trabajo y Previsión Social, consideradas como discurso performativo sobre las políticas posteriores desarrolladas por el peronismo en el gobierno. En este sentido, el autor constata y resalta la incorporación de una parte del discurso obrero al discurso peronista como característica de la vía consensual, adoptada en la nueva relación entre el Estado y los sindicatos obreros, lo que sería una característica particular de ese gobierno. Según el autor "en esa capacidad del discurso peronista de contener otros discursos está su capacidad de ir convirtiéndose en hegemónico" (Balduzzi, 1987, p. 187). Por lo tanto, según Balduzzi, en la constitución de la CNAOP se encuentra, entre otras, una demanda obrera.

En esta misma línea de trabajo se encuentra el trabajo de Inés Dussel (1990) El movimiento estudiantil en el surgimiento de la Universidad Tecnologica Nacional: Los casos de ingeniería de la UBA y la UTN (1945-1966). Si bien este estudio se centra en la comparación de los movimientos estudiantiles de ingeniería de la Universidad de Buenos Aires y de la UON-UTN la autora ofrece, en la primera parte del mismo, un detallado estudio del surgimiento de la UON.

En este sentido, la autora remarca la existencia de dos grupos disciplinarios en pugna dentro del campo de la ingeniería. Estos dos modelos de enseñanza de la ingeniería estaban representados por el ingeniero civil, con formación generalista, que iba a trabajar en obras sanitarias, ferrocarriles o en la agricultura, tareas propias de una economía agroexportadora; y el "modelo alemán", propio de un país industrializado, con una visión "no globalizante". Este último tenía peso en la Facultad de Ingeniería de La Plata, que no exigía el título de bachiller para ingresar, y en la Escuela Industrial Otto Krause. Con la sustitución de importaciones, "el modelo alemán comienza a ser más útil" (Dussel, 1990, p. 24); Pascual Pezzano, vicerrector de la UON, pertenecía a este último grupo. Fue este grupo disciplinario de la ingeniería el que contó con el apoyo del peronismo. En este sentido, era de suponerse la simpatía de este grupo por la industrialización propuesta ya desde 1944 por el gobierno, y por su aliento a la enseñanza técnica. "No demostrando la industria privada gran comprensión del problema, la alianza con los hombres del gobierno debe haberles parecido la única salida" (Dussel, 1990, p. 29): la mayoría de ellos ocupará puestos en la Comisión Nacional de Aprendizaje y en la Dirección General de Educación Técnica.

Por otra parte, el trabajo de Dussel analiza en qué medida la UON fue una universidad obrera y si constituyó o no una opción educativa democratizadora para la clase obrera. Para ello construye, en base a las distintas fuentes orales, dos periodos entre 1953 y 1966 en torno a la composición social del estudiantado. Según su análisis la democratización educativa durante el peronismo no se produjo en torno a la inclusión masiva de sectores excluidos del sistema educativo y, por lo tanto, desde un plano cuantitativo, aunque sí lo hizo desde un plano cualitativo. En este sentido, el efecto democratizador del proyecto de la UON hacia la sociedad tenía un carácter más simbólico que lo que efectivamente incorporaba, por 
cuanto la creación de una universidad obrera suponía el reconocimiento del derecho de los obreros a la educación superior, ya no al nivel de la proclama sino en la realidad. El carácter "herético" de esta institución radicaría en el hecho de que, para el discurso peronista, los obreros tenían el derecho de acceder a la educación superior, podían ser tanto educadores como educandos y tenían la posibilidad de llegar a ser dirigentes.

Otro referente insoslayable dentro de esta línea interpretativa es Marcela Mollis (1991), quien en su ya clásico artículo "La historia de la Universidad Tecnológica Nacional: una universidad para hombres y mujeres que trabajan", aborda la problemática de la Universidad Obrera Nacional desde una perspectiva específicamente universitaria, cuyo análisis se realiza sobre la base de entrevistas a testigos y protagonistas de la época, testimonios escritos oficiales, periodísticos y gremiales. La autora analiza la confrontación entre los modelos universitarios de ingeniería de la UBA por un lado, y de la UON, por el otro. Según su análisis estos dos modelos universitarios diferían en torno a la función social que desempeñarían en los distintos modelos de acumulación; el de la UBA estaría ligado al modelo agroexportador, mientras que el de la UON estaría vinculado al modelo de industrialización por sustitución de importaciones (ISI). Es, en este contexto histórico signado por una política que benefició a la burguesía industrial a través de la fuerte protección que se dio a la industrial nacional y por el incremento salarial que aumentó la capacidad de consumo del mercado interno y, por ende, su capacidad de acumulación que la UON habría tenido la finalidad de facilitar la movilidad social de los obreros y, por el otro, satisfacer los requerimientos de los sectores industriales de cada región del país. En este marco, el cambio de nombre aparece como una estrategia que adoptó dicha institución para poder sobrevivir en un escenario político adverso: resultaba prioritario desvincularse del proyecto peronista. En este sentido, la autora sostiene que después del golpe de Estado a Perón, la lucha estudiantil puso de relieve la función social de la UON, la cual trascendía las aspiraciones "peronizantes" de los trabajadores-técnicos que asistían a ella. Por lo tanto, para Mollis "el valor democratizador de la UON/UTN estuvo directamente relacionado con la oportunidad brindada a los 'trabajadores-técnicos' para formarse en una institución de nivel superior y obtener un título habilitante para el ejercicio de la profesión de ingeniero" (Mollis, 1991, p. 106), oportunidad que se encontraba limitada en la universidad tradicional.

Por su parte, Pineau (1991) va a analizar en qué medida las demandas de la clase obrera influyeron en la conformación de la CNAOP y de la UON. En este trabajo el autor adhiere a las hipótesis desarrolladas por Balduzzi (1987) y las amplía en la consideración de un caso concreto: el análisis de las demandas educacionales en los sindicatos ferroviarios en el periodo previo, paralelo y posterior al peronismo. Asimismo, adhiere a las posturas historiográficas denominadas "no rupturistas", esto es, se coloca en una posición teórica que trata de evidenciar líneas de continuidad existentes entre el peronismo y las tradiciones y culturas políticas sindicales anteriores a este. De este modo, en su construcción de una periodización para la historia de la enseñanza técnica en Argentina, el autor postula que la verdadera ruptura acontece con posterioridad a la caída del peronismo debido a la imposición de una visión tecnocrática de "preparación de recursos 
humanos" propia del desarrollismo, en oposición a la idea de calificación técnica. En suma, el autor extrae de esta periodización sus principales conclusiones: comienza afirmando que la institucionalización de la educación técnica producida en la década de 1940 continúa el proceso iniciado anteriormente y retoma sus características esenciales, mientras que el cambio institucional producido en los años 1950 marca verdaderas rupturas en este campo. En este sentido considera que la institucionalización del circuito CNAOP-UON es parte de la lucha de los sectores obreros por acceder al saber superior, en tanto elemento de continuidad entre la etapa preperonista y peronista y base de las conquistas obtenidas durante la última. Esto señalaría el perfil democratizador del proyecto.

En un trabajo posterior (Pineau, 1997), que se desarrolla específicamente en torno a la Universidad Obrera, el autor reafirma las posiciones desarrolladas en el trabajo anterior e intenta demostrar el aspecto subversivo de tal institución al afirmar que la estrategia que el peronismo desarrolla respecto de la educación superior se basó en una práctica de control de la universidad tradicional -entendida como foco opositor- y el desarrollo de otras formas universitarias en las que se modificara o invirtiera la matriz cultural de la universidad heredada. Al respecto, Pineau afirma que

hasta ese momento, los reformistas no se habían opuesto -y en realidad muchos habían bregado por- lograr el acceso de los sectores obreros a la Universidad, pero con la condición previa de que adaptaran las mismas pautas culturales que ellos, de forma tal que su pasaje por la institución subordinara su condición de obrero a la de ser universitario [...] El proyecto de la Universidad Obrera Nacional propone lo contrario: dar status universitario -y por tal, jerarquizar enormemente- a la condición obrera, a sus pautas y matrices culturales sin modificarlas, de forma tal de subordinar lo universitario a lo obrero, en una alternativa subversiva entendida en clave carnavalesca. (Pineau, 1997, p. 222)

Puede suponerse, entonces, que en estas nuevas instituciones de nivel superior el peronismo buscaba la formación de los intelectuales orgánicos del régimen. Se produjo entonces un cambio de estrategia educativa de los grupos sociales en ascenso, quienes pasaron de demandar el acceso a una institución preexistente a generar nuevas instituciones basadas en nuevas pautas, en las que las matrices culturales previas de los sujetos ocupan un lugar principal.

Por último, en un ya clásico trabajo sobre la educación técnica durante el primer peronismo que sintetiza las principales líneas de investigación de los estudios anteriormente citados, Dussel y Pineau (1995) afirman que

la creación del sistema de educación técnica [...] puede ser analizada como una de las propuestas más originales del peronismo, que se nutrió tanto de procesos políticos- culturales más amplios -lo que Sarlo denomina "saberes del pobre"- como experiencias educativas realizadas por distintos sujetos sociales. Contra lo que ha planteado la oposición de su época, y la historiografía posterior, esta creación no fue una estrategia improvisada y confusa, sino que articulaba muchas tradiciones y proyectos de peso, 
laborales, sindicales, políticos y pedagógicos; y tenía una organicidad importante, tanto interna -entre sus distintos ciclos- como en relación a los sujetos que pretendía incorporar. En su conjunto, la creación de este circuito paralelo de formación técnica habría sido uno de los aspectos en que el peronismo cuestionó con mayor fuerza al orden simbólico que estructuró al sistema educativo moderno. (Dussel \& Pineau, 1995, pp. 161-62)

Asimismo, bajo este mismo marco conceptual, Puiggrós y Bernetti (1993) estructurarán una nueva forma de interpretación histórico-educativa del fenómeno peronista sobre la base del análisis del discurso peronista, el cual

muestra que la combinación entre la inclusión de los sectores populares más abandonados por el sistema tradicional, en carácter de sujetos de la educación pública, sumada a la introducción de enunciados que relacionan la educación con el trabajo tiene un sentido subversivo respecto al discurso pedagógico tradicional, aunque con cierta tendencia a marginalizarse dentro del sistema. (Puiggrós \& Bernetti, 1993, p. 249)

Este carácter subversivo del discurso pedagógico surge nítidamente al considerarse específicamente la cuestión de la creación de la UON, puesto que

el sujeto que se sitúa en el discurso de la UON era el trabajador dignificado, y se ponían condiciones para que esa dignificación fuera legitimada. El Estado respondía a reivindicaciones largamente demandadas con un doble gesto de otorgarle una nueva identidad al trabajador -por lo tanto un nuevo lugar en la cultura política nacional- y al mismo tiempo exigirle una identificación total con el Estado-Partido. (Puiggrós \& Bernetti, 1993, p. 272)

De esta manera los autores rechazan y contestan las interpretaciones tradicionales bosquejadas alrededor del surgimiento de la Universidad Obrera, esto es, la reducción de dicha institución a medidas demagógicas o la simple respuesta a necesidades de capacitación de mano de obra de la burguesía industrial o, aun, la conquista de los trabajadores arrancada a las clases dominantes. Para los autores, la Universidad Obrera es, efectivamente, el resultado de una demanda de los trabajadores, pero reformulada y articulada en un nuevo discurso junto a una pluralidad de significantes. $Y$ es este hecho lo que hace del peronismo un fenómeno político con ribetes revolucionarios en el contexto de la historia argentina. Tanto para estos autores, como para Dussel y Pineau (1995), el potencial democratizador del circuito de educación técnica instaurado por el peronismo radica en su carácter simbólico "herético" y "subversivo".

Somoza Rodríguez (1997) construye su esquema conceptual sobre la base de la crítica a la principal tesis de Plotkin (1993), por un lado, y de Puiggrós y Bernetti (1993) por otro. El autor sostiene que la escuela no puede circunscribirse al concepto funcionalista de "agencia de adoctrinamiento". Pero tampoco considera que las reformas educativas del periodo se deban principalmente a la presión de las demandas populares. Según Somoza Rodríguez

ambas cuestiones estuvieron presentes, pero la resultante final fue la creación de un Sistema Global de Resocialización del que la escuela (sistema 
educativo formal) era solo una parte, y no sabemos si necesariamente la principal. Todas las otras modalidades, acciones e instituciones educativas formales y no formales, lo integraban igualmente, desde la Escuela Superior Peronista a la más alejada misión Monotécnicas, desde la más humilde Unidad Básica a las Facultades de Derecho, desde los campeonatos deportivos o las concentraciones de masas a la Escuela Superior del Ejército. Por resocialización debe entenderse no solamente la formación moral y cultural sino igualmente la adquisición de competencias prácticas, técnicas y profesionales para desenvolverse en la producción y en la vida cotidiana. (Somoza Rodríguez, 1997, p. 11)

De esta manera el concepto de "sistema global de resocialización", propuesto por el autor, se presenta como una instancia superadora del concepto formulado por Plotkin, por un lado, y de la interpretación de Bernetti y Puiggrós, por el otro. Asimismo el autor sostiene que si bien el peronismo produzco una segmentación del sistema educativo, esta adquiere un carácter positivo, al garantizar el ascenso social de los sectores obreros.

El último trabajo correspondiente a este línea historiográfica es Las universidades del trabajo en Argentina y Brasil: una historia de las propuestas de su creación; entre el mito y el olvido de Marcela Pronko (2003). En este la autora realiza un estudio comparativo entre la constitución de la CNAOP y su contraparte brasileña: el Servicio Nacional de Aprendizaje Industrial (SENAI). Según la autora el circuito educativo correspondiente a la CNAOP se completó en 1948 con la creación del segundo y tercer ciclos, correspondiendo este último a los estudios ofrecidos en la UON. La constitución de esta universidad respondería, en parte, al enfrentamiento que Perón sostuvo durante sus años al frente del poder ejecutivo con la universidad de cuño reformista. Según Pronko,

el gobierno intentó modificar las bases políticas de la universidad reformista surgida en 1918, que contaba con la adhesión mayoritaria de la comunidad universitaria, imponiendo una estructura que se oponía a los principios levantados por dicho movimiento, al tiempo que pretendió modificar el perfil liberal/profesionalizante de su oferta educativa. Para esto, entre otras medidas dictó dos leyes universitarias (13.031/47 y 14.297/54) e instituyó la Universidad Obrera Nacional. (Pronko, 2003, p. 180)

Asimismo, al analizar los considerandos del decreto 8014/52 que reglamenta la organización y funcionamiento de la UON, la autora concluye que "una vez más, la originalidad de la propuesta, su carácter democratizador -por el componente de la justicia social- y la supervaloración de lo 'nacional' son elementos que asociados a la doctrina justicialista, la caracterizan" (Pronko, 2003, p. 170). En el esquema de la autora, la UON constituiría tanto un intento del peronismo por modificar el perfil liberal-profesionalizante de la universidad reformista como también una instancia educativa democratizadora.

Si bien los autores pertenecientes a esta línea interpretativa estudiaron diversos aspectos del circuito educativo CNAOP-UON como ser la participación de los sindicatos, los ingenieros o los empresarios, a diferencia de la descripta en el 
apartado anterior, esta tendencia estaría caracterizada por un mayor grado de homogeneidad en cuanto a la interpretación sobre la finalidad que subyace en las propuestas de diversificación del sistema educativo: la vinculación educación-trabajo y las propuestas de diversificación del sistema responderían a las demandas de los sectores sociales no incluidos hasta el momento y la potencialidad de las políticas educativas mencionadas buscaron impulsar la promoción social de los actores involucrados. Creemos que dicha homogeneidad radica en el hecho de que la mayoría de estos autores realizaron sus trabajos en el marco del proyecto Alternativas Pedagógicas y Prospectiva Educativa en América Latina (APPEAL) de la UBA, el cual se planteó como uno de sus principales objetivos sistematizar las profusa y dispersa información sobre experiencias, hechos y discursos que han innovado, innovan o proponen innovar la educación en el futuro a partir de una calificación que contrapone alternativas pedagógicas a la pedagogía dominante (Puiggrós, 1987). La producción académica de este equipo culminaría con la publicación de ocho volúmenes de una colección denominada La historia de la educación argentina, dirigida por la Dra. Adriana Puiggrós.

\section{Trabajos del "nuevo milenio" sobre la UON}

Este apartado tiene por objeto describir una serie de trabajos publicados a partir del año 2000, que tienen como objeto de estudio la UON pero que no participan directamente de la discusión anteriormente delineada.

El primer trabajo al que haremos referencia es el de Delia Álvarez de Tomassone (2000), el cual ofrece un análisis en torno a la creación, organización y funcionamiento de la UON abarcando el periodo que va desde los debates parlamentarios de la Ley 13229 hasta la sanción del primer Estatuto de la Universidad Tecnológica Nacional. En este sentido, la autora sostiene que la creación de la UON respondería a una confluencia de factores sociales, económicos y políticos. En torno a los factores señalados, sostiene que son las razones políticas y económicas aquellas que habrían tenido más peso. Asimismo, el peronismo habría contado con una base social que le permitió sostener un proyecto educativo diversificado y pragmático; pero el papel de este no se habría limitado solamente a ampliar las demandas educativas de la clase trabajadora. En efecto, constituyó una nueva universidad tanto por el hecho de que ninguna de las existentes estuvo dispuesta a proporcionar la mano de obra especializada que demandaba la industria de ese entonces, como por el hecho de que esa era la solución más sencilla al problema de la inclusión de la clase obrera los estudios superiores universitarios. En tal sentido, la autora sostiene que ni la denominación de "obrera" ni la de "universidad" eran cuestiones fortuitas; el primero de los términos indica la intención del peronismo de incluir a los obreros dentro del sistema educativo en una institución de estudios superiores que, a diferencia de otras partes del mundo, llevaría la denominación de "universidad"; el segundo de los términos suponía rumbos y, sobre todo, expectativas diferentes. En este sentido, solo la categoría universitaria de la nueva casa de altos estudios podía satisfacer los anhelos e ilusiones de ascenso social de la clase obrera argentina, que fueron canalizados a través de la creación de esta institución: la clase trabajadora contaría ahora con la posibilidad de obtener un título universitario 
que garantizaría la realización de aquellas aspiraciones. Por último, la autora subraya que la UON luego de la autodenominada "Revolución Libertadora" pasó de ser halagada como la creación personal de Perón a ser estigmatizada por la misma razón. En efecto, tal como sostiene Álvarez, la UON luego del golpe de Estado buscó borrar todo vestigio de peronismo. La demanda de legitimación de su jerarquía universitaria respondería a esta situación, aunque no fue el gobierno de la "Revolución Libertadora" el que daría una respuesta a esta situación. En el marco de una nueva situación política caracterizada por la proscripción del peronismo, la misma oposición política que fustigó el proyecto de la UON, ahora lo apoyaba con vehemencia. La ley que sancionó la autarquía de la UON, ahora denominada oficialmente UTN, dejó atrás algunas características como el permitir el ingreso solamente a los egresados de las escuelas fábrica o, en su defecto, de las escuelas industriales de la Nación. Pero, a su vez, conservó otras características del modelo universitario anterior como por ejemplo el regionalismo, el enfoque didáctico de las clases, la asistencia obligatoria y el vínculo permanente con el aparato productivo. En relación al proceso de reestructuración de esta institución, la autora sostiene que el posicionamiento político de la institución consistente en desistir de su pasado peronista aparece como una estrategia adoptada por esta para poder sobrevivir en el marco de una dictadura de abierta represión a todo aquello identificado con dicho movimiento político (Álvarez de Tomassone, 2000).

La tesis doctoral de Fernando Nápoli (2003), por su parte, realiza un análisis sobre la Universidad Tecnológica Nacional desde su origen parlamentario hasta el año de la sanción de su primer estatuto (1948-1962). Este trabajo se desarrolla en torno al interrogante sobre si la creación de la UON fue una iniciativa planificada con el fin de atender las necesidades de la coyuntura, o bien obedeció a la lógica de una expansión distinta de los campos del saber propios de la ingeniería. La respuesta, según el autor, contempla elementos múltiples de análisis, contempla "la convergencia de ambas realidades en un proceso tendiente a la articulación de factores educativos, políticos y estratégicos" (Nápoli, 2003, p. 140).

A los largo de su trabajo, el autor sostiene múltiples consideraciones en torno a la UON. En primer lugar, esta casa de altos estudios sería inseparable del proyecto peronista de una "nueva argentina". Pero también lo sería del proceso económico imperante. Tal como sostiene, en la conformación del circuito educativo CNAOP-UON se encontraba una demanda localizada en el amplio espectro de la "sociedad civil" (Nápoli, 2003, p. 141).

Otra característica que resalta el autor respecto a la UON es que en esta institución convergen y se conjugan "el saber acreditado institucionalmente" y "el saber experiencial adquirido fuera de las claustros universitarios". En este sentido sostiene que "con la creación de la Universidad Obrera Nacional, los obreros accederían en forma masiva a la educación superior, y se instauraba una nueva valoración de la relación entre educación universitaria y el mundo del trabajo" (Nápoli, 2003, pp. 143-145). En torno al campo específicamente de la enseñanza de la ingeniería, Nápoli sostiene que una de las principales características que traería consigo la UON fue su lineamiento curricular innovador en el campo de enseñanza de la ingeniería. 
Por último, creemos necesario destacar cuál sería el lugar que ocuparía la UON en la constitución de una nueva clase política. En este sentido Nápoli destaca que esta nueva clase política, que surgiría de las filas de la UON, se diferenciaría de las tradicionales tanto por su matriz ideológica, como por su origen de clase. Para el autor, esta sería una de las variables que explicarían el apoyo del reformismo universitario al Golpe de Estado de 1955 (Nápoli, 2003).

Por otra parte, a lo largo de sus trabajos publicados sobre esta temática, Angélica Malatesta (2005, 2008 y 2010) ofrece un estudio de carácter descriptivo en torno a la Universidad Obrera Nacional. En dichos trabajos la autora resalta básicamente dos componentes innovadores en esta casa de estudios. En primer lugar, las particularidades de la relación enseñanza-aprendizaje. En este sentido Malatesta sostiene que la innovación pedagógica de la UON estaría dada por la pertinente complementación entre la explicación, la ejercitación y la experimentación, relación pedagógica nunca antes tomada en cuenta por las universidades tradicionales. En esta dirección, la autora añade que la UON privilegiaría en sus aulas los aprendizajes propios de los ámbitos laborales como la fábrica o el taller, ámbitos éstos nunca tomados en cuenta anteriormente por la enseñanza tradicional universitaria. En efecto, el "saber hacer" sostenido por Perón en sus discursos sobre la UON, encontraba su correlato en la actividad áulica de esta novel casa de estudios. Esta arista del saber no había sido tenida en cuenta en la curricula de las carreras de ingeniería hasta ese momento. El segundo aspecto que subraya Malatesta, como uno de los aspectos innovadores de la UON, es la estructura regional que ésta adquiere, cubriendo así un amplio espacio del territorio nacional (Malatesta, 2005).

En un trabajo posterior (2010) la autora añade una nueva característica innovadora de la UON: el trabajo como valor educativo. Al respecto, sostiene que

al establecerse como condición imprescindible para los alumnos de la Universidad Obrera que deben encontrarse trabajando en tareas afines o relacionadas con sus estudios de grado, este enfoque se enriquece. $Y$ esto es así, porque se introduce un concepto innovador y trascendente, esto es que el trabajo, no sólo enaltece a la persona, sino que tiene en sí mismo un valor educativo que complementa y perfecciona la formación académica, es decir que el trabajo añade peculiares e importantes aportes al conocimiento. En consecuencia, la creación de la Universidad demuestra a las claras la especial atención al trabajo y a su función social y educativa. (Malatesta, 2010, p. 79)

Por último cabe resaltar que en el esquema de Malatesta el peronismo, en un contexto signado por las demandas sociales de las clases populares hacia el Estado, accede a las mismas promoviendo, a través de la creación de la Universidad Obrera Nacional, el ascenso social de las clases trabajadoras, universalizando así el acceso a los estudios universitarios a todos los sectores sociales y garantizando, de esta manera, la justicia social (Malatesta, 2010). Tal como puede observarse, esta conclusión no se aleja demasiado de las anteriormente citadas. 
Otro trabajo que hemos incluido en este apartado es el de Sánchez Román (2007), quien aporta nuevos puntos de análisis sobre la UON. Según el autor,

la creación de la Universidad Obrera Nacional puede ser entendida como una derrota de algunos sectores de las elites económicas y sociales argentinas. Los industriales y buena parte de las elites argentinas, entre ellos los ingenieros, así lo entendieron y por ello promovieron su completa reestructuración tras la caída de Perón en 1955. Sin embargo, los logros de la Universidad fueron más simbólicos que reales [...] era la culminación simbólica de un proceso que despojaba a ciertos sectores de las elites de su pretensión de monopolizar los conocimientos más valiosos para la sociedad. (Sánchez Román, 2007, pp. 298-99)

En el esquema del autor, la instauración de la Universidad Obrera Nacional vendría a demostrar que fue el Estado quien tuvo que tomar en sus manos la educación técnica debido al desdén y la incapacidad del empresariado argentino para poder hacerlo. Asimismo, fue el gobierno peronista quien tomó en sus manos este proceso. Según Sánchez Román la UON es la materialización de un proceso cuyo origen se remonta a las primeras décadas del Siglo XX, que consiste en la creciente centralización del sistema educativo, la doctrina educativa de la Iglesia Católica y las demandas de la clase obrera en su conjunto.

Otro estudio que constituye un importante antecedente es el libro de Horacio Gaggero y Alicia Garro (2009) denominado Mejor que decir es hacer, mejor que prometer es realizar. Estado, gobierno y políticas sociales durante el peronismo (19431955), que ofrece una exhaustiva y detallada descripción sobre la configuración y el funcionamiento del sistema educativo en su conjunto durante este periodo histórico. En este sentido los autores sostienen que el peronismo habría promovido la movilidad social ascendente de la clase trabajadora. Asimismo, los hijos de los obreros eran sistemáticamente incluidos dentro del sistema educativo: la CNAOP habría sido producto de la diversificación del sistema educativo que buscaba incluir a quienes habían tenido que desertar del sistema regular de enseñanza para tener que engrosar las filas del proletariado. Por último, los autores afirman que el peronismo efectivamente generó las condiciones para la movilidad social a través de la formación de una mano de trabajo altamente calificada en el circuito educativo CNAOP-UON, incluso varios años después de la caída de este gobierno (Gaggero y Garro, 2009).

Un nuevo trabajo que hemos incluido dentro de este conjunto de estudios es la ponencia de Vanesa Jalil (2009) denominada La Universidad Obrera Nacional. Una experiencia de educación popular. La autora realiza un análisis de las líneas editoriales de los diarios La Prensa, Crítica y El Líder en torno a la Universidad Obrera Nacional. En base a este campo empírico la UON es caracterizada por Jalil como un proyecto alternativo de la clase trabajadora y, a su vez, como la inserción del poder popular en el Estado. Según el esquema de la autora, la educación popular estaría dada por el hecho de romper con el modelo universitario vigente y sería una ruptura respecto al modelo tradicional de educación oligárquica. En este sentido, Jalil sostiene que la experiencia de la UON podría analizarse en clave de educación popular, en tanto constituyó un espacio educativo subversivo frente al 
orden establecido. A su vez, destaca que horarios vespertinos, clases tipo seminario, articulación teoría-práctica y contacto directo con la producción serían aspectos pedagógicos que la distinguirían como una experiencia de carácter popular. También el hecho de que los roles entre educadores y educandos podían invertirse: los obreros no solo podían ser estudiantes sino también educadores. Por último el regionalismo sería otro rasgo por el cual la UON podría catalogarse como una experiencia de educación popular. En suma, la relación entre la UON y la educación popular, en el esquema interpretativo de Jalil, estaría dada por el hecho de que esta casa de estudios constituyó un posible instrumento para la construcción del poder de la clase trabajadora y por haber propulsado una ruptura pedagógica con la concepción cultural tradicional que se autoreservaba el espacio universitario (Jalil, 2009).

El último trabajo al que haremos referencia es la reciente tesis doctoral de Mariana Facio (2014) denominada La Cenicienta de las universidades. De la Universidad Obrera Nacional a la Universidad Tecnológica Nacional. El caso de la Facultad Regional Avellaneda (1943-1963). Este estudio de caso ofrece un análisis sobre esta institución tanto antes como después del golpe de Estado de 1955. Este estudio está centrado en la "significación social" (Facio, 2014, p. 2) que la UON tuvo para los estudiantes de la Facultad Regional Avellaneda (FRA) a través de la recolección de testimonios orales. En este sentido, para Facio la UON fue el medio a través del cual Perón consolidó su vínculo con el movimiento obrero. Asimismo cabe resaltar que, al igual que para Balduzzi, la creación de este sistema de educación técnica planificado, en donde se incluyó en un nivel universitario a la UON, fue producto de lo solicitado por los sindicatos. En efecto, según la autora, la propuesta democratizadora del peronismo traería consigo la reacción clasista tanto de la oposición, como de los ingenieros profesionales. Esta reacción llevó a que las

instituciones representativas del campo de la Ingeniería respondieran discriminando a los alumnos de la UON, por estudiar en una Universidad que ellos mismos se propusieron desprestigiar. Esta interpretación les impidió percibir sus características innovadoras, entre ellas, su carácter federal expresado en la creación de las Facultades Regionales establecidas con el objetivo de considerar las necesidades de la producción industrial y la estructura económica de cada región. (Facio, 2014, p. 60)

Según Facio, la miopía política de la oposición al peronismo no les permitió el carácter innovador del nuevo proyecto educativo. Esta situación estaría presente en los relatos de los egresados de la FRA quienes habrían sufrido descalificaciones por haber realizado sus estudios en la UON.

Con el advenimiento de la "Revolución Libertadora" en 1955, la situación de esta institución cambia radicalmente. Esta etapa trajo a la luz el nacimiento de importantes controversias en torno al papel del estado en la educación universitaria y a la organización de ese sistema en general. Para sus estudiantes, la UON se habría convertido en una bandera de lucha tanto para los estudiantes peronistas como para aquellos que no lo eran. Esta lucha estudiantil tuvo como consecuencia "no solo evitar el cierre de su casa de estudios, sino además hacer que el prejuicio antiperonista que pesaba sobre ellos fuera desestimado" (Facio, 2014, p. 94): en 
un primer momento la UON pudo subsistir gracias a la lucha estudiantil, que entre otras cosas, logró erradicar el estigma de ser la "universidad peronista".

Asimismo en el marco del gobierno constitucional de Frondizi, la percepción oficial en torno a la UON comienza a modificarse: la ahora UTN comienza a ser percibida como una herramienta al servicio del desarrollo económico. Esta circunstancia, según sostiene la autora, explica su alejamiento del peronismo y también explicaría el cambio de posicionamiento político de aquellos legisladores que, en 1948, habían denostado el proyecto político del peronismo: la autora advierte, tal como lo hace Pineau (1991), el definitivo alejamiento del sector sindical del proyecto educativo de la UON. En este sentido, una de las consecuencias de la creación de la UTN, para Facio, es que muchas de las características democratizadoras de la UON se perdieron. Aunque, según los actores entrevistados por la autora, estos cambios promovieron la jerarquización de esta casa de altos estudios (Facio, 2014).

Tal como mencionamos anteriormente, los trabajos agrupados en esta categoría se caracterizan por la alta diversidad y heterogeneidad en sus producciones. Estas van desde estudios que indagan acerca de los orígenes de la UON y la UTN, como ser el caso de Álvarez de Tomassone; trabajos que están atravesados por preocupaciones de carácter políticas y pedagógicas, como en el caso de los trabajos de Nápoli, Malatesta y Jalil, hasta estudios de caso que se centran en la "significación social" que tuvo la UON para los estudiantes de la Facultad Regional Avellaneda, en el periodo de constitución de dicha sede, a través de la recolección de testimonios orales.

\section{Consideraciones finales}

A lo largo de la reconstrucción historiográfica desplegada en el presente trabajo, puede observarse que el debate en torno a la UON aparece hegemonizado -en un primer momento- básicamente en torno a la tensión entre segmentación del sistema educativo, de un lado y democratización del mismo, por otro. En este sentido, cabe destacar que el trabajo de Somoza Rodríguez constituye un antecedente muy importante en el marco de este debate, ya que logra complementar ambas tendencias historiográficas. El autor sostiene que si bien la creación de la CNAOP y de la UON constituye una segmentación del sistema educativo, este subsistema adquiere un carácter democratizador debido a que contribuye a la promoción social de los sectores obreros. Por otra parte, reconoce un hecho que ninguno de los autores pertenecientes a lo que hemos denominado como tendencia democratizadora explicita: el "adoctrinamiento" de la juventud al interior de las instituciones educativas en el marco de la denominada "Doctrina Nacional Peronista". En este sentido, propone la utilización del concepto de "sistema global de resocialización" en detrimento de la idea funcionalista de "agencia de adoctrinamiento" de Mariano Plotkin (1993). Consideramos que este trabajo constituye una ruptura, en términos historiográficos, sobre la temática en cuestión. A partir de este artículo, a excepción del trabajo de Pronko (2003), el conjunto de los nuevos trabajos sobre la UON experimenta una gran atomización en cuanto a 
las problemáticas estudiadas en torno a esta institución, en las perspectivas teóricas utilizadas y en las fuentes analizadas. Asimismo, cabe resaltar que en todos ellos desaparecen las lecturas teleológicas sobre los fines últimos que subyacen a la creación del circuito educativo CNAOP-UON, tal como puede observarse en las dos primeras tendencias historiográficas. En este sentido, estos nuevos trabajos se centran en el estudio de diversos aspectos de la UON, a diferencia también de las tendencias historiográficas arriba mencionadas que se circunscribían al estudio de esta institución de manera más bien tangencial, en el marco de estudios más generales sobre la educación durante el primer peronismo. Cabe subrayar también que muy pocos de estos estudios se dedicaron al estudio estrictamente de la Universidad Obrera y de estos, solo algunos ofrecen un análisis de esta institución en el marco de los gobiernos postperonistas y la consiguiente reconversión de la Universidad Obrera en Universidad Tecnológica Nacional (Véase Novelli, 1986; Dussel, 1990; Mollis, 1991; Pronko, 2003; Nápoli, 2003; Álvarez de Tomassone, 2006; y Facio, 2014).

En este sentido, creemos que el relativo vacío historiográfico que existe en torno a la UON en el periodo inmediatamente posterior a la caída del peronismo se debe al hecho señalado por Álvarez de Tomassone en su trabajo, en torno a la falta de fuentes escritas ${ }^{2}$ para abordar este objeto de estudio. Por ello consideramos que el trabajo de Facio (2014) resulta sumamente revelador en materia de fuentes sobre las cuales abordar la historia de la UON. Este se centra en el análisis de la significación social que ha tenido esta institución universitaria para los estudiantes de la Facultad Regional Avellaneda a través de los testimonios orales, poco utilizados en los estudios sobre esta institución universitaria. Este estudio de caso permitió construir este objeto de estudio desde una dimensión sociocultural.

Por último, consideramos que continuar en la línea de estos trabajos podría ser fructífero a la hora de nutrir nuevas perspectivas orientadas a dar cuenta de procesos tales como la conformación y el funcionamiento efectivo de la UON bajo la órbita del gobierno peronista y la posterior reestructuración de esta casa de estudios durante la "Revolución Libertadora" primero y bajo el gobierno constitucional de Frondizi, en un segundo momento. En este sentido, es posible entonces pensar en una perspectiva metodológica integral en la que confluyan fuentes primarias documentales como asimismo los relatos en primera persona de aquellos actores que formaron parte de los acontecimientos.

\footnotetext{
2 Álvarez de Tomassone sostiene en su trabajo que tuvo serias dificultades para reunir las fuentes ya que algunas no existen en los archivos locales y otras se perdieron en los años posteriores a 1955 (Álvarez de Tomassone, 2000, p. 7).
} 


\section{Referencias bibliográficas}

Álvarez de Tomassone, D. (2000). Universidad Obrera Nacional-Universidad Tecnológica Nacional. La génesis de una universidad (1948-1962). Buenos Aires: Editorial Universitaria de la Universidad Tecnológica Nacional.

Balduzzi, J. (1987). Peronismo, saber y poder. En Hacia una pedagogía de la imaginación para América Latina (pp. 170-201). Buenos Aires: Contrapunto.

Braslavsky, C. (1985). La discriminación educativa en Argentina. Buenos Aires: FLACSO. Grupo Editorial Latinoamericano.

Dussel, I. (1990). El movimiento estudiantil en el surgimiento de la Universidad Tecnológica Nacional: Los casos de la UBA y la UTN (1945-1966). Informe final de investigación. Buenos Aires: FLACSO.

Dussel, I. \& Pineau, P. (1995). De cuando la clase obrera entró al paraíso: la educación técnica estatal en el primer peronismo. En A. Puiggrós, Historia de la educación en Argentina. Discursos pedagógicos e imaginario social durante el primer peronismo (1945-1955) (Tomo VI, pp. 107-173). Buenos Aires: Galerna.

Facio, M. (2014). "La Cenicienta de las universidades". De la Universidad Obrera Nacional a la Universidad Tecnológica Nacional. El caso de la Facultad Regional Avellaneda (19431963). Tesis Final. Magister en Ciencias Sociales del Trabajo. Facultad de Ciencias Sociales. Universidad de Buenos Aires. Argentina.

Gaggero, H. \& Garro A. (2009). Mejor que decir es hacer, mejor que prometer es realizar. Estado, gobierno y políticas sociales durante el peronismo (1943-1955) Proyectos y realidades. Buenos Aires: Biblos-Fundación Simón Rodríguez.

Jalil, V. (2009). La Universidad Obrera Nacional. Una experiencia de educación popular. XII Jornadas Interescuelas/Departamentos de Historia. Departamento de Historia, Facultad de Humanidades y Centro Regional Universitario Bariloche. Universidad Nacional del Comahue, San Carlos de Bariloche. Argentina.

Kleiner, B. (1964). Veinte años de movimiento estudiantil reformista. 1943-1963. Buenos Aires: Platina.

Malatesta, A. (2005). El surgimiento de la Universidad Obrera Nacional en la Argentina de fines de la década de 1940. Diálogos Pedagógicos, III(6), 22-33.

Malatesta, A. (2008). La etapa fundacional de la Universidad Obrera Nacional. La conexión universitaria entre el aula y el trabajo. Buenos Aires: Editorial de la Universidad Tecnológica Nacional.

Malatesta, A. (2010). La creación de la universidad obrera nacional y la hora de la industria. La conexión universitaria entre el aula y el trabajo. Córdoba: UCES.

Mollis, M. (1991). La historia de la Universidad Tecnológica Nacional: una universidad para hombres y mujeres que trabajan. Revista Realidad Económica, 99, 91-108.

Nápoli, P. (2003). Política educativa y organización académica en el período fundacional de 
la Universidad Tecnológica Nacional (1948-1962). Tesis Doctoral inédita. Univesidad Católica de La Plata, Argentina.

Novelli, N. (1986). Movimientos estudiantiles en la Universidad Tecnológica Nacional (19531958). Rosario: Pontificia Universidad Católica Argentina, Facultad de Derecho y Ciencias Sociales, Instituto de Historia.

Pineau, P. (1991). Sindicatos, Estado y educación técnica (1936-1968). Buenos Aires: CEAL.

Pineau, P. (1997). De zoológicos y carnavales: las interpretaciones sobre la Universidad Obrera Nacional en Cucuzza Héctor Rubén. Estudios de Historia de la Educación durante el Primer Peronismo, 1943-1955. Buenos Aires: Universidad Nacional de Lujan. Editorial Los libros del Riel.

Plotkin, M. (1993). Mañana es San Perón. Propaganda, rituales políticos y educación en el régimen peronista (1946-1955). Buenos Aires: EDUNTREF.

Pronko, M. (2003). Las Universidades del trabajo en Argentina y Brasil. Una historia de las propuestas de su creación. Entre el mito y el olvido. Montevideo: Cintefor/OIT.

Puiggrós, A. \& Bernetti, J. (1993). Peronismo: cultura política y educación (1945-1955). Buenos Aires: Galerna.

Puiggrós, A. (1987). Hacia una pedagogía de la imaginación para América Latina. Buenos Aires: Contrapunto.

Sánchez Román, J. A. (2007). De las "escuelas de Artes y Oficios" a la Universidad Obrera Nacional: Estado, elites y educación técnica en Argentina, 1912-1955. Madrid: Universidad Complutense de Madrid.

Somoza Rodríguez, J. (1997). Interpretaciones sobre el proyecto educativo del primer peronismo. De "agencia de adoctrinamiento" a "instancia procesadora de demandas". En Anuario de Historia de la Educación, No1, Sociedad argentina de Historia de la Educación/ Universidad Nacional de San Juan. San Juan. Argentina.

Tedesco, J. C. (1978). Educación e industrialización en argentina. Informe del Proyecto de desarrollo y Educación en América Latina y el Caribe de la UNESCO/CEPAL/PNDU. Santiago de Chile.

Tedesco, J. C. (1980). La educación argentina (1930-1955). Buenos Aires: CEAL.

Tedesco, J. C. (1986). Educación y sociedad (1880-1945). Buenos Aires: Siglo XXI.

Weinberg, G. (1984). El descontento y la promesa. Buenos Aires: Belgrano. 